\title{
Plantas medicinais referenciadas por raizeiros no município de Jataí, estado de Goiás
}

SOUZA, L.F." ${ }^{*}$; DIAS, R.F.2; GUILHERME, F.A.G. ${ }^{\prime}$; COELHO, C.P. ${ }^{1}$

'Universidade Federal de Goiás, Regional Jataí, Unidade Acadêmica Especial de Biociências, Lab. de Taxonomia Vegetal e Herbário Jataiense. Cx postal 03. Jataí, GO, 75801-615; 'Biota Projetos e Consultoria Ambiental, Rua 86-C, $n^{\circ}$ 64, Setor Sul, Goiânia, GO, CEP 74083-360. *Autor para correspondência: lufs_go@yahoo.com.br

RESUMO: Este trabalho objetivou pesquisar as plantas medicinais referenciadas por raizeiros do município de Jataí-GO, evidenciando o Valor de Uso Reportado (VUR) e a conexão com os níveis filogenéticos atuais. Com cerca de 200 anos de história, Jataí localiza-se no Planalto Central do

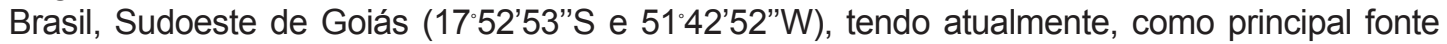
de renda o agronegócio. Para a seleção dos raizeiros e coleta dos dados aplicou-se o método bola de neve e a técnica de entrevistas semiestruturadas. Determinou-se a etnoespécie, parte usada, uso, modo de preparo, sintomas / doenças relacionando aos sistemas corporais. Foram reportadas 515 referências etnobotânicas para 112 etnoespécies principalmente dos clados Fabídeas, Lamídeas, e Campanulídeas. Sobressaíram as etnoespécies Pé-de-perdiz (Croton antisyphilliticus), Sangra-dágua (C. urucurana), Pau-terra-de-folha-larga (Qualea grandiflora), Ervade-Santa Maria (Chenopodium album), Amaro-leite (Operculina alata), Algodãozinho-do-campo (Cochlospermum regium), Cavalinha (Equisetum hiemale) e Jaborandi (Piper aduncum), com VUR maior que 10. Os sistemas corporais mais importantes com relação ao número de etnoespécies relatadas foram respiratório, digestivo, circulatório e tegumentar. As etnoespécies mais versáteis em uso nos sistemas corporais foram Copaíba (Copaifera langsdorffii), Pé-de-perdiz (Croton antisyphiliticus), Cavalinha (Equisetum hiemale), Alecrim (Rosmarinus officinalis) e Fruta-delobo (Solanum paniculatum). A prática da medicina tradicional em Jataí evidencia a conexão entre a escolha de plantas e os níveis filogenéticos derivados. Algumas destas etnoespécies estão na listagem de plantas medicinais que o Ministério da Saúde do Brasil escolheu para a realização de monografias, fato que fortalece o valor do conhecimento do uso da flora nas práticas da medicina tradicional.

Palavras chave: Etnobotânica, Plantas nativas, Cerrado, Planalto Central.

ABSTRACT: Medicinal Plants referenced by "raizeiros" from Jataí county, Goiás state. This study aimed to research medicinal plants referenced by "raizeiros" from Jataí-GO, showing the Reported Use Value (RUV) and connection with current phylogenetic levels. With nearly 200 years of history, Jataí is located in the Central Plateau of Brazil, Southwest Goiás (17'52'53 "S and $51^{\circ} 42^{\prime} 52^{\prime \prime} \mathrm{W}$ ), where the main source of income is agribusiness. For the "raizeiros" selection and data collection the snowball method and semi-structured interview techniques were applied. The ethnospecies, used part, usage, method of preparation for estimatedReported Value of Use (VU). There were 515 related ethnopharmacological citations of 112 ethnospecies, mainly Fabídeas, Lamídeas and Campanulídeas. Pé-de-perdiz (Croton antisyphilliticus), Sangra-dágua (C. urucurana), Pau-terra-de-folha-larga (Qualea grandiflora), Erva-de-Santa Maria (Chenopodium album), Amaro-leite (Operculina alata), Algodãozinho-do-campo (Cochlospermum regium), Cavalinha (Equisetum hiemale) andJaborandi (Piper aduncum), Pau-terra-de-folha-larga (Qualea grandiflora), Erva-de-Santa Maria (Chenopodium album), Amaro-leite (Operculina alata), Algodãozinho-do-campo (Cochlospermum regium), Cavalinha (Equisetum hiemale) andJaborandi (Piper aduncum)highlightedmorethan10RUV. The most important bodily systems in the number of reported plants were respiratory, digestive, circulatory and integumentary. The most versatile, useful plant systems were Copaíba (Copaiferalangsdorffii), Pé-de-perdiz (Crotonantisyphiliticus), Cavalinha (Equisetumhiemale), Rosemary (Rosmarinusofficinalis) and Fruita-de-lobo (Solanumpaniculatum).The practice of traditional medicine in Jataí reveals the link between the choice of plants and derived phylogenetic levels. Many referenced species are used medicinally in the Cerrado, including some that are part of the national health care system's list,

Recebido para publicação em 23/09/2015 
for the realization of monographs, which strengthen the knowledge of these traditional medicine practices in Goiás.

Key words: Ethnobotany, native plants, Cerrado, Central Plateau.

\section{INTRODUÇÃO}

Desde tempos remotos, as plantas são usadas para fins de diagnóstico, profilaxia ou cura, usos que se perpetuaram na história. Em 1978, a Organização Mundial da Saúde (OMS, 1978) reconheceu a Fitoterapia como uma prática oficial e recomendou a difusão dos conhecimentos necessários para o seu uso. WHO (2002) observou que $85 \%$ da população mundial usa plantas medicinais e elaborou uma série de resoluções considerando o valor das plantas na medicina tradicional e sugerindo o envolvimento dos serviços de saúde regionais.

Plantas medicinais são aquelas que apresentam compostos químicos com ação farmacológica em animais, que embora bem diversificados, não raro, são específicos para determinado grupo vegetal. Segundo Kaplan et al.(1994), o distanciamento filogenético entre as espécies vegetais é diretamente proporcional às diferenças químicas entre elas. Os vegetais apresentam uma rede de reações químicas versáteis conferindo ampla variabilidade estrutural ao seu metabolismo o que faz com que uma única espécie produza centenas de substâncias (Gottlieb \& Borin 2012). O homem, ao longo dos séculos, vem selecionando estas substâncias para a resolução dos problemas orgânicos (Gottlieb \& Borin 2002).

As práticas da medicina tradicional variam muito de país para país e de região para região, sendo influenciadas por fatores culturais, históricos, sociais e filosóficos, sendo importantes para a escolha da farmacopeia local. Para demonstrar a segurança e eficácia dessa farmacopeia, há necessidade de pesquisas que forneçam evidências seguras das plantas nas práticas da medicina tradicional. Ainda há poucas pesquisas para referendar com segurança a eficácia das espécies vegetais na medicina tradicional de Goiás.

Esta pesquisa, de cunho etnobotânico, reporta as espécies vegetais referenciadas por raizeiros em Jataí, visando fornecer evidências que fortaleçam o conhecimento destas nas práticas da medicina tradicional de Goiás, com vistas a pesquisas futuras nas áreas de ecológica, agronômica, validação farmacológica e prospecção química.

\section{MATERIAL E MÉTODO}

O município de Jataí localiza-se no Planalto
Central, microrregião Sudoeste de Goiás (17052'53"S e 51042'52'W, 708 m. de elevação), tendo começado sua história em setembro de 1836, com a formação de fazenda de criação de gado. Os momentos importantes foram a criação da Freguesia do Divino Espírito Santo de Jatay (1864), a transformação em Vila do Paraíso (1882) e a criação do município de Jatay (1890). A etimologia do nome Jataí (Jaatay) advém de espécies do gênero Hymenaea, que em tupi-guarani refere-se aos frutos secos de pericarpo endurecido (Chiaradia, 2008). O gentílico de quem nasce em Jataí é jataiense. Com área de $7.174,228 \mathrm{Km}$, o município apresenta remanescentes florestais, savânicas e campestres, porém predominam as monoculturas de soja, milho, girassol e cana de açúcar, ocasionando perda de cerca de $60 \%$ de áreas nativas (Oliveira, 2007). Os rios da região fazem parte da bacia do Paranaíba, alta bacia do Paraná e Prata, com predominância latossolos profundos. O clima é tropical com médias anuais de $24,6^{\circ} \mathrm{C}$ e precipitação média anual de $1.747,4 \mathrm{~mm}$, verão chuvoso de outubro a março e inverno seco de abril a setembro (Silva et al. 2006).

Para alcançar o objetivo proposto, buscamos identificar e quantificar a diversidade botânica filogenética referenciada pelos raizeiros (especialistas que comercializam plantas medicinais ou seus produtos), relacionar essa diversidade às doenças dos sistemas corporais, salientando o valor de uso reportado das etnoespécies (VUR). O estudo foi conduzido ao longo do ano de 2010, usando o método bola de neve (Albuquerque et al. 2008) para selecionar os raizeiros, sendo o primeiro aquele que trabalha na feira local. Os raizeiros reportaram sobre as plantas usadas considerando as variáveis etnoespécies (ET), parte usada (PU), doenças ou sintomas (DS) e formas de uso (FU). Coletamos o material botânico em quintais e áreas nativas do município com a presença do raizeiro. Categorizamos as etnoespécies em exóticas (EX), nativas conhecidas (NC) e nativas desconhecidas (ND), sendo que amostras das duas primeiras categorias foram coletadas em qualquer fase de vida, enquanto da terceira coletamos em fase reprodutiva. Registramos os dados em caderneta de campo, digitamos em planilha, para a somatória das variáveis e análise do percentual reportado. O material botânico foi depositado no Herbário Jataiense prof. Germano Guarim Neto (HJ) da Universidade Federal de Goiás (Regional Jataí),

Rev. Bras. PI. Med., Campinas, v.18, n.2, p.451-461, 2016. 
onde ocorreu a determinação por comparação com amostras reprodutivas. A classificação seguiu APG III (2009) e o nome dos táxons e autores está de acordo com Forzza et al. (2015). Relacionamos as doenças e sintomas (DS) aos sistemas corporais (SISTCORP) seguindo os dados mínimos ideais para sistemas de informação de saúde segundo a Classificação Internacional de Funcionalidade, Incapacidade e Saúde (OMS 2004). O Valor de Uso Reportado (VUR) refere-se ao número total de usos referenciados para cada etnoespécie (Gomez-Beloz 2002), valorizando cada espécie pelo conjunto total de usos que lhe é reputado. Analisamos também o valor de uso para os sistemas corporais com a finalidade de determinar as espécies mais versáteis referenciadas pelos raizeiros de Jataí.

\section{RESULTADO E DISCUSSÃO \\ Perfil do raizeiro de Jataí - GO}

A metodologia permitiu incluir toda a população de raizeiros da área urbana do município, sendo sete no total. A Tabela 1 indica que o raizeiro jataiense apresenta em média 65 anos de idade, tempo médio de residência no município igual a 56 anos e trabalha como raizeiro em média há 31 anos. Todos são naturais de Goiás, tem renda familiar até dois salários mínimos, a maioria é do gênero masculino, etnia parda, religião católica, com instrução até o ensino fundamental.

\section{Etnobotânica}

Os raizeiros referenciaram 113 etnoespécies dentro das divisões Sphenophyta (uma etnoespécie: Cavalinha) e Angiospermas (112), observadas na Tabela 2. Foram reportadas 515 referências etnobotânicas sendo que Cavalinha (Sphenophyta, Equisetum hiemale) obteve VUR = $11(2,1 \%)$, usada contra osteoporose, anemia, ansiedade, cálculos renais, infecção dos rins e bexiga. É uma planta exótica plantada em quintais com fins terapêuticos e ornamentais. As angiospermas somaram 504 referências etnobotânicas, distribuídas em
Angiospermas basais (16,5\%) e Eudicotiledôneas $(81,4 \%)$. Destacaram os clados Fabídeas (28 espécies e 151 referências), Lamídeas (28/112) e Malvídeas (20/94) somando juntos $65 \%$ das espécies e $70 \%$ das referências (Figura 1). Entre as ordens, destacaram Malpighiales, Lamiales, Fabales, Myrtales, Asterales e Gentianales com 58 espécies $(50 \%)$ e 289 referências (55\%). Analisando outros trabalhos do uso de plantas medicinais observa-se essa mesma relação; em trabalho de revisão sobre a riqueza de plantas medicinais mato-grossenses, Guarim Neto \& Morais (2003), levantaram 96 famílias, das quais cerca de $60 \%$ pertencem aos clados Fabídeas, Malvídeas, Asterideas, Lamídeas e Campanulídeas. Em 2003, Leonti et al., ao analisarem a flora medicinal de Popoluca (México), concluíram que as cinco famílias mais usadas são Asteraceae, Piperaceae, Fabaceae, Euphorbiaceae e Lamiaceae, a maioria pertencente aos grupos derivados. Na região nordeste do Brasil, trabalhos citam Fabaceae, Euphorbiaceae, Cucurbitaceae (Fabídeas), Malvaceae (Malvídea), Lamiaceae (Lamídea) e Asteraceae (Asterídea), como as famílias mais representativas (Ribeiro et al., 2014; Oliveira \& Lucena, 2015; Silva et al., 2015). Esta prática se deve certamente a fatores como: 1.pool gênico que permite maior diversidade aos grupos derivados, maior amplitude de ambientes colonizados, produção e ocorrência de compostos químicos; 2.facilidade de obtenção do vegetal e 3.seleção inconsciente desses compostos através da seleção consciente das plantas, pelos especialistas tradicionais.

As famílias e gêneros que se destacaram em diversidade de espécies e referências de uso estão listados na Tabela 1. Entre as famílias salientam Euphorbiaceae, Fabaceae, Asteraceae e Lamiaceae com $26 \%$ das espécies e $30 \%$ das referências. Para a maioria dos gêneros foram referenciadas de uma a duas espécies; aqueles com referência de duas espécies foram Citrus, Croton, Mentha, Plectranthus, Smilax, Solanum e Tabebuia.

TABELA 1. Perfil do Raizeiro de Jataí, Goiás.

\begin{tabular}{ccccccccc}
\hline Raizeiros & gênero & idade & etnia & $\begin{array}{c}\text { Anos que reside } \\
\text { no munícipio }\end{array}$ & $\begin{array}{c}\text { Anos que } \\
\text { trabalha como } \\
\text { raizeiro }\end{array}$ & religião & $\begin{array}{c}\text { renda familiar } \\
\text { (salários) }\end{array}$ & $\begin{array}{c}\text { grau de } \\
\text { instrução }\end{array}$ \\
\hline R1 & masculino & 75 & parda & 51 & 40 & católica & 1 a 2 & fundamental \\
R2 & masculino & 58 & parda & 58 & 35 & católica & 1 a 2 & fundamental \\
R3 & feminino & 63 & parda & 60 & 35 & protestante & 1 a 2 & fundamental \\
R4 & masculino & 83 & parda & 76 & 45 & protestante & 1 a 2 & fundamental \\
R5 & masculino & 57 & branca & 45 & 20 & católica & 1 a 2 & fundamental \\
R6 & feminino & 69 & branca & 50 & 30 & católica & 1 a 2 & fundamental \\
R7 & masculino & 49 & parda & 49 & 15 & protestante & 1 a 2 & Médio \\
\hline
\end{tabular}

Rev. Bras. Pl. Med., Campinas, v.18, n.2, p.451-461, 2016. 
TABELA 2. Lista das etnoespécies (ET) usadas por raizeiros na zona urbana do o município de Jataí (GO), de acordo a família e espécie botânicas, sistema corporal (SISTCORP), doenças ou sintomas (D/S), parte usada $(P U)$, forma de preparo (PREP) e $n^{\circ}$. de registro no Herbário Jataiense (RHJ)

\begin{tabular}{|c|c|c|c|c|c|c|c|}
\hline ET & FAMÍLIA & ESPÉCIE & SISTCORP & $\mathrm{D} / \mathrm{S}$ & PU & PREP & $\mathrm{RHJ}$ \\
\hline Abacate & Lauraceae & Persea americana Mill. & $\begin{array}{l}\text { Digestivo } \\
\text { Urinário }\end{array}$ & $\begin{array}{l}\text { Disenteria } \\
\text { Problemas Renais }\end{array}$ & $\begin{array}{l}\text { Brotos } \\
\text { Folhas } \\
\text { Sementes }\end{array}$ & $\begin{array}{l}\text { Infuso } \\
\text { Decocto } \\
\text { Óleo }\end{array}$ & 308 \\
\hline Abacaxi & Bromeliaceae & Ananas comosus (L.) Merr. & $\begin{array}{l}\text { Imune, respiratório } \\
\text { Urinário }\end{array}$ & $\begin{array}{l}\text { Vermífugo, catarro nos } \\
\text { pulmões, tosse, Diurético }\end{array}$ & Frutos & Suco & 100 \\
\hline Abóbora & Cucurbitaceae & Cucurbita pepo L. & Digestivo, sensorial & Má digestão, dor de ouvido & Flores & Suco & 101 \\
\hline Açafrão & Zingiberaceae & Curcuma longa L. & Digestivo, urinário & Má digestão, Diurético & Raiz & Infuso & 102 \\
\hline Acerola & Malpighiaceae & Malpighia glabra L. & Respiratório & Gripe & Folhas & Decocto & 1107 \\
\hline Açoita cavalo & Malvaceae & $\begin{array}{l}\text { Luehea grandiflora Mart. \& } \\
\text { Zucc. }\end{array}$ & Circulatório & Antiglicerídeos & Caule & Infuso & 2065 \\
\hline Agrião & Brassicaceae & Nasturtium officinale R. Br. & $\begin{array}{l}\text { Circulatório } \\
\text { Respiratório } \\
\text { Urinário }\end{array}$ & $\begin{array}{l}\text { Depurativo } \\
\text { Bronquite } \\
\text { Diurético }\end{array}$ & $\begin{array}{l}\text { Flores } \\
\text { folhas }\end{array}$ & Suco & 103 \\
\hline Alcachofra & Asteraceae & Cynara scolymus L. & $\begin{array}{l}\text { Digestivo } \\
\text { Endócrino } \\
\text { Urinário }\end{array}$ & $\begin{array}{l}\text { Problemas no fígado } \\
\text { Vias biliares, obesidade } \\
\text { Diurético }\end{array}$ & Folhas & Decocto & 104 \\
\hline Alecrim & Lamiaceae & Rosmarinus officinalisL. & $\begin{array}{l}\text { Cardiovascular, } \\
\text { nervoso, Digestivo } \\
\text { Urinário, respiratório }\end{array}$ & $\begin{array}{l}\text { Acalma o coração } \\
\text { Calmante má digestão } \\
\text { Diurético, Bronquite }\end{array}$ & Folhas & $\begin{array}{l}\text { Infuso / macerado } \\
\text { Inalar a fumaça }\end{array}$ & 992 \\
\hline $\begin{array}{l}\text { Alecrim do } \\
\text { campo }\end{array}$ & Bignoniaceae & $\begin{array}{l}\text { Anemopaegma arvense (Vell.) } \\
\text { Stellf. }\end{array}$ & Nervoso & $\begin{array}{l}\text { Energético } \\
\text { Tônico }\end{array}$ & Raiz & Garrafada & 6868 \\
\hline Alface & Asteraceae & Lactuca sativa L. & $\begin{array}{l}\text { Imune,nervoso } \\
\text { Musculoesquelético }\end{array}$ & $\begin{array}{l}\text { Inchaços, insônia } \\
\text { Contusões }\end{array}$ & Folhas & Infuso/emplasto & 105 \\
\hline Alfavaca & Lamiaceae & Ocimum campechianum Mill. & Respiratório & Gripe, Tosse & Folhas & Infuso & 1127 \\
\hline $\begin{array}{l}\text { Algodãozinho } \\
\text { do campo }\end{array}$ & Bixaceae & $\begin{array}{l}\text { Cochlospermum regium (Mart. } \\
\text { Ex. Schrank.) Pilger }\end{array}$ & Reprodutivo & $\begin{array}{l}\text { Dores, inflamação do útero } \\
\text { e ovários }\end{array}$ & Folhas/raiz & Decocto / garrafada & 6718 \\
\hline Algodoeiro & Malvaceae & Gossypium hyrsutum L. & $\begin{array}{l}\text { Tegumentar } \\
\text { reprodutivo }\end{array}$ & $\begin{array}{l}\text { Acne, infecção de pele } \\
\text { dores no útero e ovário } \\
\text { Inflamações em geral }\end{array}$ & Folhas & Sumo & 953 \\
\hline Amaro leite & Convolvulaceae & Operculina alata (Ham.) Urb. & Circulatório & Depurativo & $\begin{array}{l}\text { Batata / } \\
\text { raiz }\end{array}$ & $\begin{array}{l}\text { Doce / Garrafada } \\
\text { macerado/ polvilho }\end{array}$ & 998 \\
\hline $\begin{array}{l}\text { Angico } \\
\text { branco }\end{array}$ & Fabaceae & $\begin{array}{l}\text { Anadenanthera colubrina } \\
\text { (Vell.) Brenan }\end{array}$ & Respiratório & Bronquite & Caule & Decocto & 105 \\
\hline $\begin{array}{l}\text { Angico do } \\
\text { cerrado }\end{array}$ & Fabaceae & $\begin{array}{l}\text { Anadenanthera peregrina var. } \\
\text { falcata(Benth.) Altschul }\end{array}$ & Respiratório & $\begin{array}{l}\text { Bronquite, problemas } \\
\text { pulmonares, gripe }\end{array}$ & $\begin{array}{l}\text { Caule, } \\
\text { resina }\end{array}$ & $\begin{array}{l}\text { Decocto, macerado } \\
\text { na pinga / vinho, } \\
\text { xarope }\end{array}$ & 3210 \\
\hline $\begin{array}{l}\text { Aroeira } \\
\text { branca }\end{array}$ & Anacardiaceae & Lithrea molleoides (Vell.) Engl. & Musculoesquelético & Reumatismo & caule & Banho do decocto & 1148 \\
\hline $\begin{array}{l}\text { Arnica da } \\
\text { serra }\end{array}$ & Asteraceae & Lychnophora ericoides Mart. & Musculoesquelético & Contusões & Folhas & Alcoolatura & 106 \\
\hline Aroeira & Anacardiaceae & $\begin{array}{l}\text { Myracrodruom urundeuva } \\
\text { Allemão }\end{array}$ & $\begin{array}{l}\text { Digestivo respiratório } \\
\text { Musculoesquelético }\end{array}$ & $\begin{array}{l}\text { Disenteria, úlceras no } \\
\text { estômago Gripe ciático } \\
\text { Gota reumatismo }\end{array}$ & Caule & $\begin{array}{l}\text { Beber o decocto } \\
\text { ou banho na parte } \\
\text { afetada }\end{array}$ & 3818 \\
\hline Assa peixe & Asteraceae & $\begin{array}{l}\text { Vernonanthura ferruginea } \\
\text { (Less.) H.Rob. }\end{array}$ & Respiratório & $\begin{array}{l}\text { Bronquite asmática e } \\
\text { simples, Expectorante, } \\
\text { Gripe, Pneumonia, } \\
\text { problemas pulmonares }\end{array}$ & Folhas & Infuso & 1546 \\
\hline Arruda & Rutaceae & Ruta graveolens $\mathrm{L}$. & $\begin{array}{l}\text { Reprodutivo } \\
\text { tegumentar }\end{array}$ & $\begin{array}{l}\text { Cólicas menstruais, } \\
\text { Menstruação difícil e } \\
\text { dolorosa } \\
\text { Inflamações dos olhos }\end{array}$ & $\begin{array}{l}\text { Todo o } \\
\text { Ramo }\end{array}$ & Banho do infuso & 107 \\
\hline Babosa & Asphodelaceae & Aloe vera (L.) Burm. F. & $\begin{array}{l}\text { Circulatório } \\
\text { Digestivo } \\
\text { Tegumentar }\end{array}$ & $\begin{array}{l}\text { Hemorroidas } \\
\text { Má digestão } \\
\text { Erisipelas, queimaduras } \\
\text { Inflamações em geral } \\
\text { Queda de cabelo }\end{array}$ & Mucilagem & Emplasto / pilula & 108 \\
\hline Baru & Fabaceae & Dipteryx alata (Vogel) Taub. & Musculoesquelético & Coluna & Caule & Decocto & 3882 \\
\hline Bálsamo & Fabaceae & Myroxylon peruiferum L. f. & $\begin{array}{l}\text { Imune respiratório } \\
\text { Sensorial }\end{array}$ & $\begin{array}{l}\text { Inchaços gripe } \\
\text { Dores }\end{array}$ & $\begin{array}{l}\text { Caule } \\
\text { sementes }\end{array}$ & Decocto & 5844 \\
\hline Barbatimão & Fabaceae & $\begin{array}{l}\text { Stryphnodendron polyphyllum } \\
\text { Mart. }\end{array}$ & $\begin{array}{l}\text { Imune } \\
\text { Tegumentar } \\
\text { Reprodutivo }\end{array}$ & $\begin{array}{l}\text { Infecções em geral } \\
\text { Cicatrizante } \\
\text { Infecção uterina } \\
\text { Leucorréia } \\
\text { Problemas vaginais }\end{array}$ & $\begin{array}{l}\text { Folhas } \\
\text { Cascas do } \\
\text { caule }\end{array}$ & $\begin{array}{l}\text { Banho } \\
\text { Garrafada } \\
\text { Decocto:ducha } \\
\text { vaginal } \\
\text { Banho de assento }\end{array}$ & 5872 \\
\hline
\end{tabular}


TABELA 2. Lista das etnoespécies (ET) usadas por raizeiros na zona urbana do o município de Jataí (GO), de acordo a família e espécie botânicas, sistema corporal (SISTCORP), doenças ou sintomas (D/S), parte usada $(P U)$, forma de preparo (PREP) e $n^{\circ}$. de registro no Herbário Jataiense (RHJ)

continuação...

\begin{tabular}{|c|c|c|c|c|c|c|c|}
\hline Boldo & Lamiaceae & $\begin{array}{l}\text { Plectranthus barbatus } \\
\text { Andrews }\end{array}$ & Digestivo & $\begin{array}{l}\text { Desintoxica o fígado, má } \\
\text { digestão }\end{array}$ & Folhas & Infuso, sumo & 109 \\
\hline Buchinha & Cucurbitaceae & Luffa operculata (L.) Cogn & Respiratório & Sinusite & Frutos & Alcoolatura & 110 \\
\hline Cigana & Bignoniaceae & $\begin{array}{l}\text { Adenocalymma } \\
\text { nodosum (Silva Manso) } \\
\text { L.G.Lohmann }\end{array}$ & Circulatório & Depurativo & Raiz & Decocto & 1513 \\
\hline $\begin{array}{l}\text { Cajuzinho do } \\
\text { campo }\end{array}$ & Anacardiaceae & Anacardium humile A.St - Hill & Digestivo & Gastrite & Raiz & Decocto / pó & 7044 \\
\hline Caju & Anacardiaceae & Anacardium occidentale L. & Digestivo & Úlcera gástrica e nervosa & Raiz & Pó & 499 \\
\hline Cardo santo & Papaveraceae & Argemone mexicana L. & Respiratório & Pneumonia & Sementes & Decocto & 117 \\
\hline Carambola & Oxalidaceae & Averrhoa carambola L. & Urinário & Problemas Renais & Folhas & Decocto & 116 \\
\hline Canela & Lauraceae & $\begin{array}{l}\text { Cinnamomum zeylanicum } \\
\text { Breyn. }\end{array}$ & $\begin{array}{l}\text { Circulatório } \\
\text { Endócrino }\end{array}$ & $\begin{array}{l}\text { Antianêmico colesterol alto } \\
\text { Antidiabete }\end{array}$ & $\begin{array}{l}\text { Caule } \\
\text { folhas }\end{array}$ & Infuso & 113 \\
\hline Copaiba & Fabaceae & Copaifera langsdorffii Desf. & $\begin{array}{l}\text { Endócrino } \\
\text { Tegumentar } \\
\text { Imune } \\
\text { Reprodutivo }\end{array}$ & $\begin{array}{l}\text { Antidiabete } \\
\text { Cicatrizante curar umbigo } \\
\text { de recém nascido, próstata } \\
\text { Antibiótico alto valor } \\
\text { medicinal. }\end{array}$ & $\begin{array}{l}\text { Óleo } \\
\text { Resina } \\
\text { Caule }\end{array}$ & $\begin{array}{l}\text { Gotas na água } \\
\text { Pingar no local } \\
\text { Pó na comida } \\
\text { Decocto }\end{array}$ & 4107 \\
\hline $\begin{array}{l}\text { Cana de } \\
\text { macaco }\end{array}$ & Zingiberaceae & Costus spiralis Roscoe & Urinário & Problemas renais & $\begin{array}{l}\text { Caule } \\
\text { folhas } \\
\text { flores }\end{array}$ & Decocto & 1013 \\
\hline $\begin{array}{l}\text { Capim } \\
\text { cidreira }\end{array}$ & Poaceae & $\begin{array}{l}\text { Cymbopogon citratus (DC) } \\
\text { Stapf }\end{array}$ & Nervoso & Calmante & Folhas & Infuso & 114 \\
\hline $\begin{array}{l}\text { Capim pé de } \\
\text { galinha }\end{array}$ & Poaceae & Cynodon dactylon (L.) Pers. & Respiratório & Pneumonia & Raiz & Decocto & 4581 \\
\hline $\begin{array}{l}\text { Chapéu de } \\
\text { couro }\end{array}$ & Alismataceae & $\begin{array}{l}\text { Ecchinodorus grandiflorus } \\
\text { Mitch. }\end{array}$ & Circulatório & Depurativo & Folhas & Infuso & 871 \\
\hline Cavalinha & Equisetaceae & Equisetum hiemale L. & $\begin{array}{l}\text { Circulatório } \\
\text { Musculoesquelético } \\
\text { Nervoso } \\
\text { Urinário }\end{array}$ & $\begin{array}{l}\text { Antianêmico } \\
\text { Osteoporose } \\
\text { Ansiedade } \\
\text { Cálculos e infecção renais } \\
\text { bexiga }\end{array}$ & $\begin{array}{l}\text { Folhas } \\
\text { brotos }\end{array}$ & Decocto & 119 \\
\hline Carajiru & Bignoniaceae & $\begin{array}{l}\text { Fridericia chica (Bonpl.) } \\
\text { L.G.Lohmann }\end{array}$ & Imune & Câncer & Folhas & Decocto & 115 \\
\hline Cipó suma & indet & Indet & Reprodutivo & Próstata & Caule & Pó diluído na água & 120 \\
\hline Carobinha & Bignoniaceae & Jacaranda decurrens Cham & Circulatório & Depurativo & Raiz & Decocto & 1194 \\
\hline $\begin{array}{l}\text { Cordão de } \\
\text { frade }\end{array}$ & Lamiaceae & $\begin{array}{l}\text { Leonotis nepetaefolia (L.) } \\
\text { R.Br. }\end{array}$ & $\begin{array}{l}\text { Musculoesquelético } \\
\text { reprodutivo }\end{array}$ & $\begin{array}{l}\text { Gota } \\
\text { Afrodisíaco } \\
\end{array}$ & $\begin{array}{l}\text { Todo o } \\
\text { Ramo Raiz } \\
\end{array}$ & $\begin{array}{l}\text { Infuso } \\
\text { Macerado na pinga }\end{array}$ & 122 \\
\hline Camomila & Asteraceae & Matricaria chamomilla L. & $\begin{array}{l}\text { Digestivo } \\
\text { Nervoso }\end{array}$ & $\begin{array}{l}\text { Má digestão, Insônia } \\
\text { Problemas intestinais }\end{array}$ & $\begin{array}{l}\text { Flores, } \\
\text { folhas }\end{array}$ & Infuso & 112 \\
\hline Cipó imbé & Araceae & $\begin{array}{l}\text { Philodendron bipinnatifidum } \\
\text { Schott. }\end{array}$ & Musculoesquelético & Coluna & Fruto seco & Emplasto & 2018 \\
\hline $\begin{array}{l}\text { Congonha } \\
\text { de bugre }\end{array}$ & Rubiaceae & $\begin{array}{l}\text { Rudgea viburnoides (Cham.) } \\
\text { Benth. }\end{array}$ & Urinário & Problemas Renais & Folhas & Infuso & 1448 \\
\hline Chuchu & Cucurbitaceae & Sechium edule (Jacq.) Sw. & Nervoso & Calmante & $\begin{array}{l}\text { Frutos } \\
\text { maduros }\end{array}$ & Polvilho & 3858 \\
\hline Confrei & Boraginaceae & Symphytum oflicinale L. & Tegumentar & $\begin{array}{l}\text { Cicatrizante } \\
\text { Contusões }\end{array}$ & Folhas & $\begin{array}{l}\text { Banho } \\
\text { Sumo em jejum }\end{array}$ & 121 \\
\hline Caraiba & Bignoniaceae & $\begin{array}{l}\text { Tabebuia aurea (Silva Manso) } \\
\text { Benth. \& Hook.f. ex S. Moore }\end{array}$ & $\begin{array}{l}\text { Circulatório } \\
\text { respiratório }\end{array}$ & $\begin{array}{l}\text { Depurativo } \\
\text { Gripe, tosse }\end{array}$ & $\begin{array}{l}\text { Caule } \\
\text { raiz }\end{array}$ & $\begin{array}{l}\text { Decocto } \\
\text { macerado na pinga }\end{array}$ & 984 \\
\hline $\begin{array}{l}\text { Catinga de } \\
\text { mulata }\end{array}$ & Asteraceae & Tanacetum vulgare $\mathrm{L}$. & Cardiovascular & Problemas no Coração & $\begin{array}{l}\text { Todo o } \\
\text { Ramo }\end{array}$ & Infuso & 118 \\
\hline Capitão & Combretaceae & Terminalia argentea Mart. & Respiratório & Gripe & $\begin{array}{l}\text { Caule } \\
\text { folhas }\end{array}$ & Xarope & 1620 \\
\hline Caferana & Asteraceae & Vernonia condensata Baker & Digestivo, Imune & $\begin{array}{l}\text { Problemas no fígado } \\
\text { vermífugo }\end{array}$ & Folhas & Macerada na água & 111 \\
\hline Douradinha & Rubiaceae & $\begin{array}{l}\text { Palicourea coreacea A.-St } \\
\text { - Hill. }\end{array}$ & Urinário & Problemas Renais & Folhas & Decocto & 1011 \\
\hline Erva cidreira & Verbenaceae & Lippia alba(Mill.)N.E.Br. & $\begin{array}{l}\text { Circulatório nervoso } \\
\text { sensorial }\end{array}$ & $\begin{array}{l}\text { Pressão alta Calmante } \\
\text { dor de } \\
\text { Cabeça }\end{array}$ & Folhas & Infuso & 986 \\
\hline $\begin{array}{l}\text { Erva de } \\
\text { bicho }\end{array}$ & Polygonaceae & $\begin{array}{l}\text { Polygonum hydropiperoides } \\
\text { Michx. }\end{array}$ & Imune & Infecções em geral & Folhas & Infuso & 957 \\
\hline $\begin{array}{l}\text { Erva de } \\
\text { lagarto }\end{array}$ & Salicaceae & Casearia sylvestris Sw. & $\begin{array}{l}\text { Digestivo } \\
\text { Musculoesquelético } \\
\text { Tegumentar }\end{array}$ & $\begin{array}{l}\text { Úlcera gástrica } \\
\text { Reumatismo } \\
\text { Úlceras dérmicas }\end{array}$ & Folhas & Infuso & 4862 \\
\hline
\end{tabular}


TABELA 2. Lista das etnoespécies (ET) usadas por raizeiros na zona urbana do o município de Jataí (GO), de acordo a família e espécie botânicas, sistema corporal (SISTCORP), doenças ou sintomas (D/S), parte usada (PU), forma de preparo (PREP) e $n^{\circ}$. de registro no Herbário Jataiense (RHJ)

continuação...

\begin{tabular}{|c|c|c|c|c|c|c|c|}
\hline Embaúba & Urticaceae & Cecropia pachystachia Trícul & Endócrinourinário & $\begin{array}{l}\text { Antidiabete, problemas } \\
\text { Renais }\end{array}$ & $\begin{array}{l}\text { Brotos } \\
\text { seiva }\end{array}$ & $\begin{array}{l}\text { Decocto } \\
\text { In natura }\end{array}$ & 2080 \\
\hline $\begin{array}{l}\text { Erva de } \\
\text { santa maria }\end{array}$ & Amaranthaceae & Chenopodium album L. & $\begin{array}{l}\text { Imune Tegumentar } \\
\text { Musculoesquelético }\end{array}$ & $\begin{array}{l}\text { Vermífugo,lesão, } \\
\text { ferimentos } \\
\text { Luxação, osso quebrado, } \\
\text { contusões }\end{array}$ & $\begin{array}{l}\text { Toda a } \\
\text { planta }\end{array}$ & $\begin{array}{l}\text { Mascar, comer o } \\
\text { pó, ferver no leite, } \\
\text { Sumo, Banho do } \\
\text { decocto }\end{array}$ & 940 \\
\hline Espinafre & Amaranthaceae & Spinacea oleracea L. & Circulatório & Antianêmico & Folhas & Salada & 123 \\
\hline $\begin{array}{l}\text { Gabiroba } \\
\text { peluda }\end{array}$ & Myrtaceae & $\begin{array}{l}\text { Campomanesia pubescens } \\
\text { (Mart. ex DC.) O.Berg }\end{array}$ & Urinário & Problemas Renais & Folhas & Infuso & 1493 \\
\hline Gengibre & Zingiberaceae & Zingiber officinale Roscoe & Respiratório & $\begin{array}{l}\text { Expectorante inflamação de } \\
\text { garganta }\end{array}$ & Raiz & Gargarejo do infuso & 1742 \\
\hline $\begin{array}{l}\text { Guaraná da } \\
\text { Amazonia }\end{array}$ & Sapindaceae & Paullinia cupana L. & Reprodutivo & Afrodisíaco & Folhas & Garrafada & 124 \\
\hline Goiabeira & Myrtaceae & Psidium guajava L. & Digestivo & Afta, disenteria & Brotos & Infuso & 582 \\
\hline Gervão & Verbenaceae & $\begin{array}{l}\text { Stachytarpheta cayennensis } \\
\text { (Rich.) Vahl }\end{array}$ & Tegumentar & Cicatrizante, contusões & Folhas & Sumo & 4474 \\
\hline $\begin{array}{l}\text { Hortelã } \\
\text { baiano }\end{array}$ & Lamiaceae & $\begin{array}{l}\text { Plectrantus amboinicus (Lour.) } \\
\text { Spreng. }\end{array}$ & $\begin{array}{l}\text { Imune } \\
\text { Respiratório }\end{array}$ & FebreBronquite, falta de ar & Folhas & $\begin{array}{l}\text { Infuso } \\
\text { Macerado }\end{array}$ & 125 \\
\hline $\begin{array}{l}\text { Hortelã } \\
\text { miúdo }\end{array}$ & Lamiaceae & Mentha crispa L. & Digestivo, imune & Má digestão vermífugo & Folhas & Infuso & 126 \\
\hline Imbiruçu & Malvaceae & $\begin{array}{l}\text { Pseudobombax grandiflorum } \\
\text { (Cav.) A.Robyns }\end{array}$ & Nervoso & Calmante & Caule & Decocto & 4377 \\
\hline Ipê roxo & Bignoniaceae & $\begin{array}{l}\text { Handroanthus impetiginosus } \\
\text { (Mart. ex DC.) Mattos }\end{array}$ & $\begin{array}{l}\text { Imune } \\
\text { Tegumentar } \\
\text { Urinário } \\
\end{array}$ & $\begin{array}{l}\text { Anti-infeccioso } \\
\text { Infecções de feridas } \\
\text { Diurético }\end{array}$ & Caule & $\begin{array}{l}\text { Decocto } \\
\text { Banho }\end{array}$ & 6960 \\
\hline Ipê branco & Bignoniaceae & $\begin{array}{l}\text { Tabebuia roseoalba (Ridl.) } \\
\text { Sandwith }\end{array}$ & Tegumentar & Infecções de feridas & Caule & Banho & 127 \\
\hline Jaborandi & Piperaceae & Piper aduncum L. & $\begin{array}{l}\text { Respiratório } \\
\text { Tegumentar }\end{array}$ & $\begin{array}{l}\text { Inflamação de garganta } \\
\text { Limpeza de pele }\end{array}$ & Folhas & $\begin{array}{l}\text { Infuso } \\
\text { Macerado }\end{array}$ & 6716 \\
\hline Japecanga & Smilacaceae & Smilax poliantha Steud. & $\begin{array}{l}\text { Circulatório } \\
\text { reprodutivo }\end{array}$ & $\begin{array}{l}\text { Depurativo } \\
\text { Gonorreia }\end{array}$ & Raiz & Decocto & 1999 \\
\hline Jarrinha & Aristolochiaceae & $\begin{array}{l}\text { Aristolochia esperanzae Mart. } \\
\text { \& Zucc. }\end{array}$ & $\begin{array}{l}\text { Digestivo } \\
\text { reprodutivo }\end{array}$ & $\begin{array}{l}\text { Má digestão } \\
\text { Próstata }\end{array}$ & $\begin{array}{l}\text { Raiz } \\
\text { Caule }\end{array}$ & Decocto & 6771 \\
\hline $\begin{array}{l}\text { Jatobá da } \\
\text { mata }\end{array}$ & Fabaceae & Hymenaea courbaril L. & $\begin{array}{l}\text { Reprodutivo } \\
\text { respiratório }\end{array}$ & $\begin{array}{l}\text { Próstata } \\
\text { Bronquite }\end{array}$ & Caule & $\begin{array}{l}\text { Decocto } \\
\text { Macerado no vinho }\end{array}$ & 4108 \\
\hline Jucá & Fabaceae & Caesalpinia ferrea Mart. & $\begin{array}{l}\text { Circulatório } \\
\text { Sensorial } \\
\text { Tegumentar }\end{array}$ & $\begin{array}{l}\text { Hemorroidas } \\
\text { Inflamações dos olhos } \\
\text { Ferimentos }\end{array}$ & Raiz & Decocto & 128 \\
\hline Jurubeba & Solanaceae & Solanum paniculatum L. & $\begin{array}{l}\text { Digestivo, } \\
\text { Endócrino, Imune } \\
\text { Musculoesquelético }\end{array}$ & $\begin{array}{l}\text { Problemas no fígado } \\
\text { Antidiabete } \\
\text { Infecções em geral } \\
\text { Reumatismo }\end{array}$ & Frutos & $\begin{array}{l}\text { Decocto macerado } \\
\text { na pinga / vinho }\end{array}$ & 2005 \\
\hline Laranjeira & Rutaceae & Citrus aurantium L. & Imune, respiratório & Febre / gripe, resfriado & Folhas & Infuso & 327 \\
\hline Lima & Rutaceae & Citrus limmeta Risso & $\begin{array}{l}\text { Imune } \\
\text { Respiratório }\end{array}$ & $\begin{array}{l}\text { Febre malina de criança } \\
\text { Gripe recolhida }\end{array}$ & Folhas & Infuso & 129 \\
\hline Lobeira & Solanaceae & Solanum lycocarpum St. Hill. & Digestivo & Má digestão & $\begin{array}{l}\text { Frutos } \\
\text { seco }\end{array}$ & Polvilho & 7351 \\
\hline Macelinha & Asteraceae & $\begin{array}{l}\text { Achyrocline albicans (Lam.) } \\
\text { DC. }\end{array}$ & Digestivo & Disenteria & $\begin{array}{l}\text { Todo o } \\
\text { Ramo }\end{array}$ & Infuso & 6670 \\
\hline Maleiteira & Fabaceae & Bowdichia virgilioides Kunth & Endócrino & Antidiabete & Caule & Decocto & 6882 \\
\hline Mamacadela & Moraceae & Brosimum gaudichaudii Trícul & $\begin{array}{l}\text { Circulatório } \\
\text { tegumentar }\end{array}$ & $\begin{array}{l}\text { Depurativo acne infecção de } \\
\text { pele vitiligo }\end{array}$ & Raiz & $\begin{array}{l}\text { Decocto } \\
\text { Garrafada }\end{array}$ & 1670 \\
\hline \multirow[b]{2}{*}{ Mamão } & \multirow[b]{2}{*}{ Caricaceae } & \multirow[b]{2}{*}{ Carica papaya L. } & \multirow[b]{2}{*}{$\begin{array}{l}\text { Digestivo, } \\
\text { Respiratório, Imune }\end{array}$} & \multirow[b]{2}{*}{$\begin{array}{l}\text { Cólicas infantis, disenteria } \\
\text { Bronquite vermífugo }\end{array}$} & \multirow{2}{*}{$\begin{array}{l}\text { Flores } \\
\text { Frutos } \\
\text { Mastigar } \\
\text { sementes }\end{array}$} & Infuso & 981 \\
\hline & & & & & & & \\
\hline $\begin{array}{l}\text { Manacá do } \\
\text { cerrado }\end{array}$ & Rutaceae & $\begin{array}{l}\text { Spiranthera odoratissima } \\
\text { A.St.-Hil. }\end{array}$ & Musculoesquelético & Reumatismo & Raiz & Infuso & 7369 \\
\hline Mandioca & Euphorbiaceae & Manihot esculenta L. & Circulatório & Antianêmico & Folhas & Pó na comida & 980 \\
\hline Milho & Poaceae & Zea mays L. & Urinário & $\begin{array}{l}\text { Cálculos renais Diurético } \\
\text { infecções urinárias }\end{array}$ & Estigma & Infuso & 118 \\
\hline Negramina & Siparunaceae & Siparuna guianensis Aubl. & $\begin{array}{l}\text { Tratamento } \\
\text { espiritual }\end{array}$ & Banho de descarrego & Folhas & Banho & 1997 \\
\hline
\end{tabular}


TABELA 2. Lista das etnoespécies (ET) usadas por raizeiros na zona urbana do o município de Jataí (GO), de acordo a família e espécie botânicas, sistema corporal (SISTCORP), doenças ou sintomas (D/S), parte usada (PU), forma de preparo (PREP) e $n^{\circ}$. de registro no Herbário Jataiense (RHJ)

continuação...

\begin{tabular}{|c|c|c|c|c|c|c|c|}
\hline $\begin{array}{l}\text { Nó de } \\
\text { cachorro }\end{array}$ & Malpighiaceae & $\begin{array}{l}\text { Heteropterys aphrodisiaca O. } \\
\text { Mach. }\end{array}$ & Reprodutivo & Afrodisíaco & Raiz & Garrafada & 130 \\
\hline Noni & Rubiaceae & Morinda citrifolia L. & Todos & Muito valor medicinal & Frutos & Suco & 131 \\
\hline Olho de Boi & Ebenaceae & Diospyros hispida A.DC & $\begin{array}{l}\text { Tratamento } \\
\text { espiritual }\end{array}$ & Mau olhado & Sementes & $\begin{array}{l}\text { Colocar atrás da } \\
\text { porta de casa }\end{array}$ & 501 \\
\hline Pé de perdiz & Euphorbiaceae & Croton antisyphiliticus (Mart.) & $\begin{array}{l}\text { Circulatório } \\
\text { Tegumentar } \\
\text { reprodutivo }\end{array}$ & $\begin{array}{l}\text { Depurativo } \\
\text { Úlceras no estômago } \\
\text { erupções da pele DST/sífilis }\end{array}$ & Raiz & $\begin{array}{l}\text { Garrafada / } \\
\text { decocto }\end{array}$ & 1850 \\
\hline $\begin{array}{l}\text { Pau terra } \\
\text { folha larga }\end{array}$ & Vochysiaceae & Qualea grandiflora Mart. & $\begin{array}{l}\text { Digestivo } \\
\text { Respiratório }\end{array}$ & $\begin{array}{l}\text { Problemas intestinais e no } \\
\text { no fígado. Tosse }\end{array}$ & $\begin{array}{l}\text { Caule, } \\
\text { folhas }\end{array}$ & Decocto & 1690 \\
\hline Pé de anta & Bignoniaceae & $\begin{array}{l}\text { Cybistax anthisyphilitica } \\
\text { (Mart.) Mart. }\end{array}$ & Digestivo & Problemas no fígado & Caule & Decocto & 1020 \\
\hline $\begin{array}{l}\text { Pimenta de } \\
\text { macaco }\end{array}$ & Annonaceae & $\begin{array}{l}\text { Xylopia aromatica (Lam.) } \\
\text { Mart. }\end{array}$ & Respiratório & Inflamação de garganta & Sementes & Infuso & 2598 \\
\hline Poejo & Lamiaceae & Mentha pulegium L. & $\begin{array}{l}\text { Imune } \\
\text { Respiratório }\end{array}$ & $\begin{array}{l}\text { Febre de criança } \\
\text { Descongestionante nasal, } \\
\text { Gripe }\end{array}$ & $\begin{array}{l}\text { Todo o } \\
\text { Ramo }\end{array}$ & Infuso & 977 \\
\hline Quina & Loganiaceae & $\begin{array}{l}\text { Strychnos pseudoquina A.St } \\
\text { - Hill }\end{array}$ & Tegumentar & Queda de cabelo & Folhas & $\begin{array}{l}\text { Lavar o cabelo com } \\
\text { o decocto }\end{array}$ & 995 \\
\hline Quininha & Malpighiaceae & Galphimia australis Chodat & Digestivo & Má digestão & Raiz & Decocto & 133 \\
\hline Romã & Lythraceae & Punica granatum $\mathrm{L}$. & $\begin{array}{l}\text { Respiratório } \\
\text { Reprodutivo }\end{array}$ & $\begin{array}{l}\text { Inflamação de garganta } \\
\text { Problemas no ovário }\end{array}$ & Frutos & $\begin{array}{l}\text { Gargarejo do } \\
\text { decocto } \\
\text { Banho de assento } \\
\text { garrafada }\end{array}$ & 134 \\
\hline $\begin{array}{l}\text { Sangra } \\
\text { dágua }\end{array}$ & Euphorbiaceae & Croton urucurana Baill. & $\begin{array}{l}\text { Imune } \\
\text { Reprodutivo } \\
\text { Tegumentar }\end{array}$ & $\begin{array}{l}\text { Infecções em geral } \\
\text { Infecção uterina } \\
\text { Cicatrizante } \\
\text { Erisipelas erupções da pele }\end{array}$ & $\begin{array}{l}\text { Caule / } \\
\text { leite }\end{array}$ & $\begin{array}{l}\text { Beber o decocto } \\
\text { das cascas do } \\
\text { caule ou o leite } \\
\text { diluido na água } \\
\text { e fazer banho no } \\
\text { local afetado. }\end{array}$ & 947 \\
\hline Sene & Fabaceae & Cassia angustifólia Vahl. & Circulatório & Depurativo & Raiz & Decocto & 135 \\
\hline $\begin{array}{l}\text { Salsa } \\
\text { paredão }\end{array}$ & Araceae & Anthurium affine Schott & Circulatório & Depurativo & Batata & Infuso & 6855 \\
\hline $\begin{array}{l}\text { Sofre dos } \\
\text { rins quem } \\
\text { quer }\end{array}$ & Annonaceae & $\begin{array}{l}\text { Duguetia furfuracea (A.St.- } \\
\text { Hil.) Saff. }\end{array}$ & Urinário & Problemas Renais & Raiz & Decocto & 568 \\
\hline Suma branca & Indet & Indet & Circulatório & Depurativo & Raiz & Infuso & 136 \\
\hline Salsa & Apiaceae & $\begin{array}{l}\text { Petroselinum crispum (Mill.) } \\
\text { A.W.Hill }\end{array}$ & Reprodutivo & Cólicas menstruais & $\begin{array}{l}\text { Todo o } \\
\text { Ramo }\end{array}$ & Infuso & 936 \\
\hline Sucupira & Fabaceae & Pterodon pubescens Vogel & $\begin{array}{l}\text { Digestivo } \\
\text { Reprodutivo } \\
\text { Respiratório }\end{array}$ & $\begin{array}{l}\text { Má digestão } \\
\text { Infecção de mulher } \\
\text { problema uterino } \\
\text { Inflamação de garganta }\end{array}$ & $\begin{array}{l}\text { Caule / } \\
\text { sementes }\end{array}$ & $\begin{array}{l}\text { Decocto, macerado } \\
\text { no vinho, macerado } \\
\text { na água }\end{array}$ & 228 \\
\hline Sabugueiro & Adoxaceae & $\begin{array}{l}\text { Sambucus australis Cham. \& } \\
\text { Schltdl. }\end{array}$ & $\begin{array}{l}\text { Imune } \\
\text { Respiratório }\end{array}$ & Febre e gripe de criança & Flores & Decocto & 2611 \\
\hline Salsa nania & Smilacaceae & Smilax fluminensis Griseb. & $\begin{array}{l}\text { Circulatório } \\
\text { tegumentar }\end{array}$ & $\begin{array}{l}\text { Depurativo infecção no } \\
\text { couro cabeludo, lepra }\end{array}$ & Batata & $\begin{array}{l}\text { Garrafada/infuso } \\
\text { Banho do decocto }\end{array}$ & 4410 \\
\hline Salsaparrilha & Smilacaceae & Smilax poliantha Steud. & Circulatório & Depurativo & Raiz & Infuso & 1999 \\
\hline Tanchagem & Plantaginaceae & Plantago major L. & $\begin{array}{l}\text { Digestivo } \\
\text { Tegumentar }\end{array}$ & $\begin{array}{l}\text { Disenteria } \\
\text { Cicatrizante, contusões }\end{array}$ & Folhas & Infuso & 988 \\
\hline Tropeiro & Connaraceae & Connarus suberosus Planch. & Cardiovascular & Problemas no Coração & Folhas & Infuso & 872 \\
\hline Tiborna & Apocynaceae & $\begin{array}{l}\text { Himatanthus obovatus (Mar.) } \\
\text { Plumel }\end{array}$ & Respiratório & Pneumonia & $\begin{array}{l}\text { Raiz } \\
\text { Leite }\end{array}$ & $\begin{array}{l}\text { Infuso } \\
\text { Tomar gotas na } \\
\text { água }\end{array}$ & 931 \\
\hline Urtiguinha & Euphorbiaceae & $\begin{array}{l}\text { Cnidoscolus albomaculatus I. } \\
\text { M. Johnst }\end{array}$ & $\begin{array}{l}\text { Circulatório } \\
\text { Musculoesquelético } \\
\text { reprodutivo }\end{array}$ & $\begin{array}{l}\text { Depurativo } \\
\text { Coluna } \\
\text { Próstata } \\
\end{array}$ & Raiz & Infuso & 1310 \\
\hline $\begin{array}{l}\text { Velame } \\
\text { branco }\end{array}$ & Apocynaceae & $\begin{array}{l}\text { Mandevilla velame (A. St.-Hil.) } \\
\text { Pichon }\end{array}$ & Circulatório & Depurativo & $\begin{array}{l}\text { Folhas / } \\
\text { raiz }\end{array}$ & Infuso & 137 \\
\hline
\end{tabular}

Rev. Bras. PI. Med., Campinas, v.18, n.2, p.451-461, 2016. 


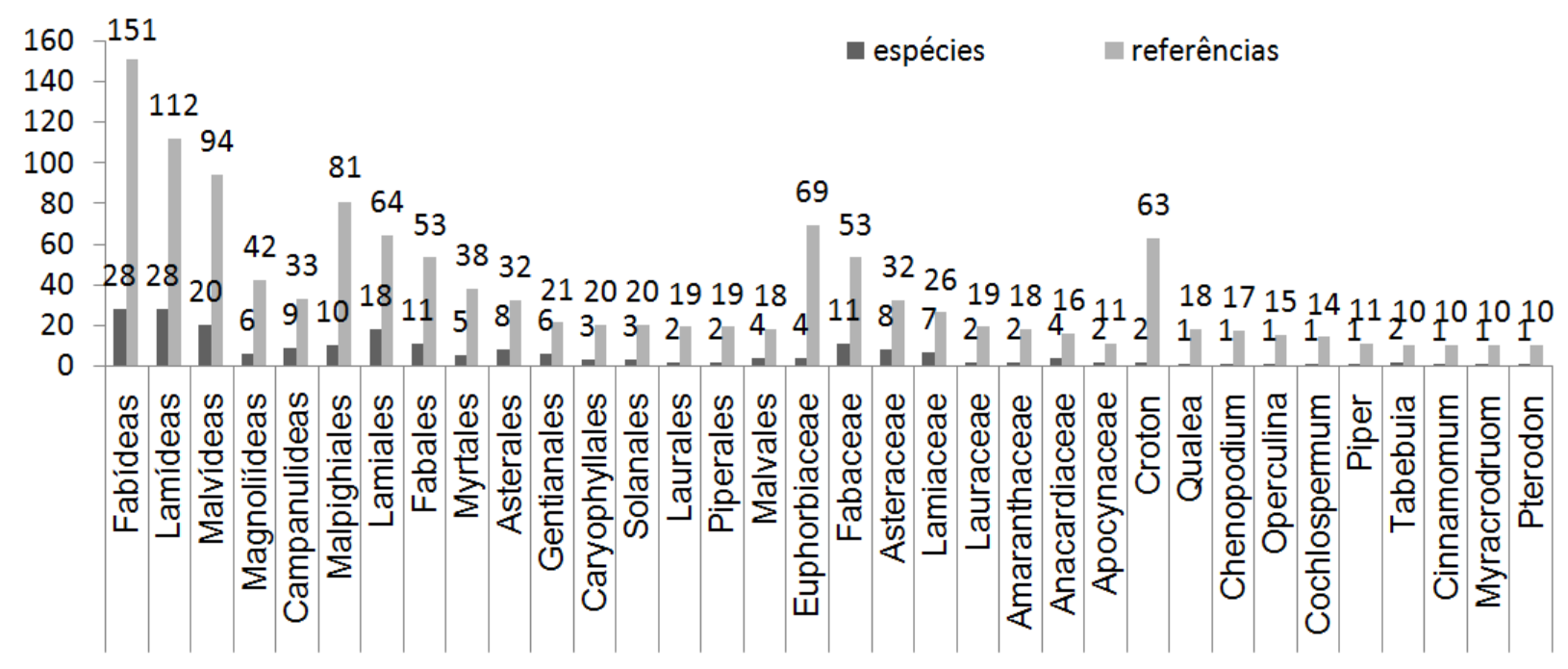

FIGURA 1. Grupos filogenéticos mais reportados pelos raizeiros de Jataí-GO.

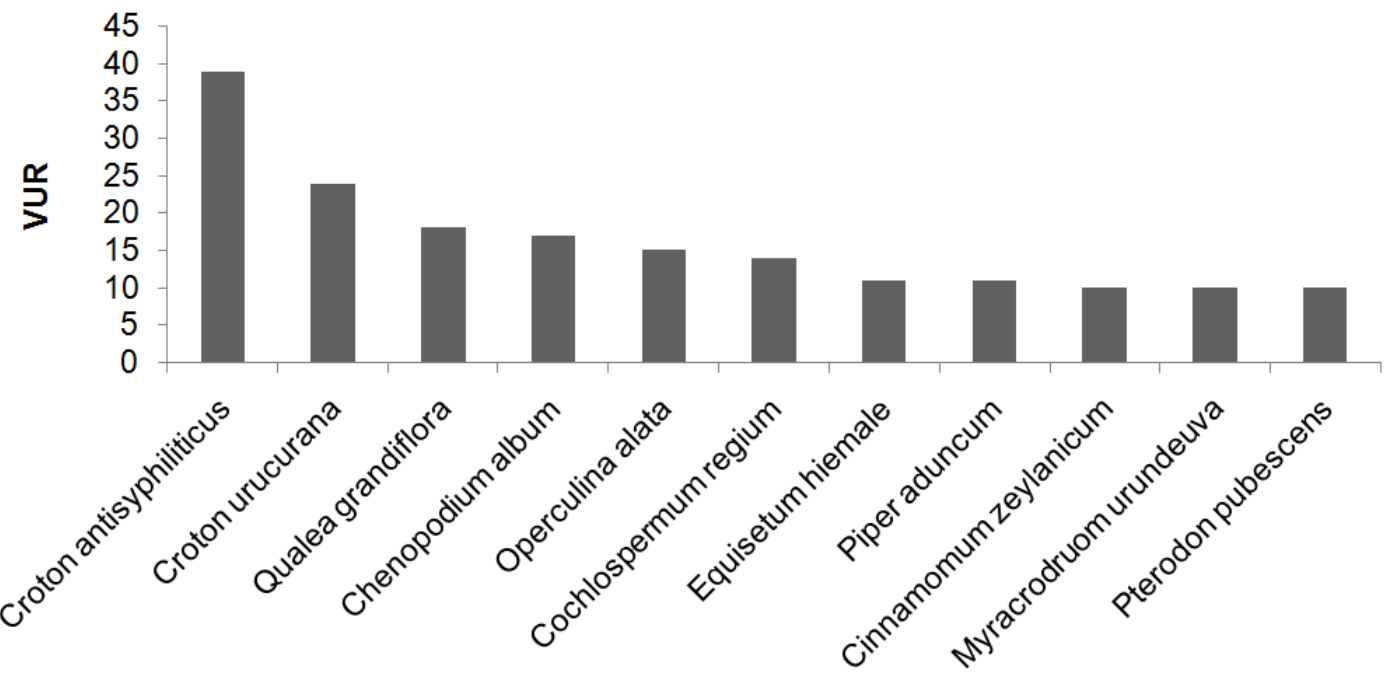

FIGURA 2. Espécies com maior Valor de Uso Relatado (VUR) entre os raizeiros de Jataí-GO.

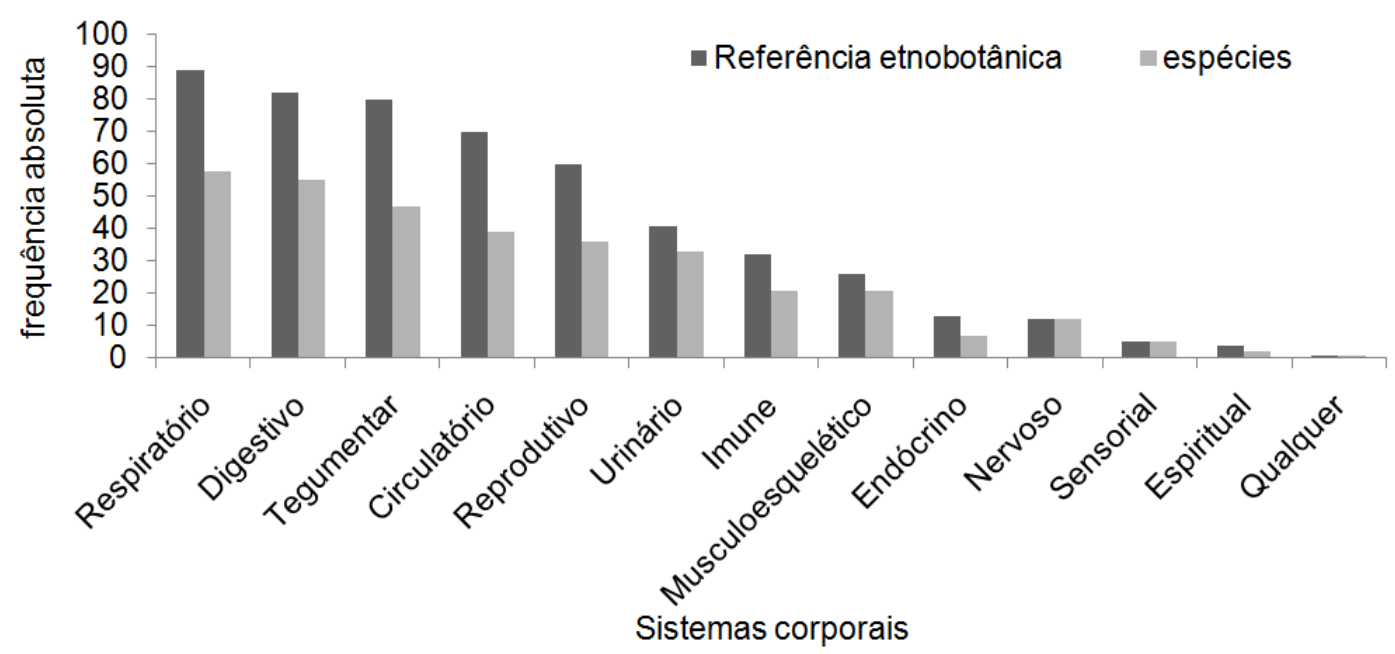

FIGURA 3. Representatividade dos Sistemas corporais considerando a frequência de espécies referenciadas pelos raizeiros de Jataí-GO. 
Outros trabalhos em Goiás e em regiões do Cerrado tem referido essas famílias e gêneros nas praticas de medicina tradicional (Guarim Neto \& Morais, 2003; Villa - Verde et al., 2003; Souza, 2007; Silva \& Proença 2008).

Considerando que o VUR é o total de usos reportados para cada planta (Gomez-Beloz, 2002), neste trabalho sobressaem as espécies da Figura 2, com destaque para Croton antisyphilliticus e C. urucurana; embora seja composta por plantas relativamente tóxicas, Euphorbiaceae apresenta espécies que o homem aprendeu domesticar e manejar em seu benefício, tanto na alimentação quanto na medicina, por ex. os diversos usos da mandioca (Manihot esculenta L.). Neste trabalho, a raiz do C. antisyphilliticus foi indicada para os males de sífilis e outras DST, erupções da pele, úlceras no estômago e depurativo. A casca do caule e o látex de C. urucurana foram indicados como cicatrizante, contra erisipelas, erupções da pele, infecção uterina e infecções em geral. Outros trabalhos evidenciam o valor destas espécies para os mesmos males
(Barros, 1982; Cruz, 1995; Lorenzi \& Matos, 2002; Villa-Verde et al. 2003; Morais et al. 2005; Souza, 2007; Silva \& Proença, 2008). Especificamente para C. antisyphilliticus em revisão de plantas medicinais do Brasil, Ferner et al. (2006), reportam trabalhos citando seu uso que remontam ao século XIX, para a cura de feridas e úlceras.

As doenças que os raizeiros relataram permitiram elencar dez sistemas corporais (SC) e um espiritual (Figura 3), sendo que aqueles com mais referencias de plantas foram os respiratório $(14,6 \%)$ circulatório (13\%), tegumentar $(10 \%)$ e digestivo $(8,1 \%)$.

As etnoespécies úteis mais versáteis nos sistemas corporais foram pé de perdiz (Croton antisyphiliticus), alecrim (Rosmarinus officinalis), copaiba (Copaifera langsdorffii), cavalinha (Equisetum hiemale) e fruta de lobo (Solanum paniculatum). São referenciadas para vários tipos de doenças, como demonstrado na Tabela 2, apresentando ampla potencialidade medicinal no município estudado. Neste quesito, apenas alecrim

TABELA 3. Espécies mais versáteis em relação aos sistemas corporais.

\begin{tabular}{|c|c|c|c|c|}
\hline Espécie & Sistema corporal & Doença & Parte usada & Forma de uso \\
\hline \multirow{6}{*}{ Copaifera langsdorffii } & Endócrino & Antidiabete & Óleo & Gotas na água \\
\hline & Imune & Alto valor medicinal & Resina & Pó na comida \\
\hline & & Antibiótico & Óleo & Gotas na água \\
\hline & Reprodutivo & Problemas na próstata & Caule & Decocto \\
\hline & Tegumentar & Cicatrizante & & \\
\hline & & $\begin{array}{l}\text { Curar umbigo de recém } \\
\text { nascido }\end{array}$ & Óleo & Pingar no local \\
\hline \multirow{4}{*}{ Croton antisyphiliticus } & Circulatório & Depurativo & \multirow{4}{*}{ Raiz } & \multirow{4}{*}{ Decocto / garrafada } \\
\hline & Digestivo & Úlceras no estômago & & \\
\hline & Reprodutivo & DST, Sífilis & & \\
\hline & Tegumentar & Erupções da pele & & \\
\hline \multirow{6}{*}{ Equisetum hiemale } & Circulatório & Antianêmico & \multirow{6}{*}{$\begin{array}{l}\text { Folhas, } \\
\text { brotos }\end{array}$} & \multirow{6}{*}{ Decocto } \\
\hline & Musculoesquelético & Osteoporose & & \\
\hline & Nervoso & Ansiedade & & \\
\hline & Urinário & Cálculos renais & & \\
\hline & & Infecção dos rins e bexiga & & \\
\hline & & Inflamação de bexiga & & \\
\hline \multirow{5}{*}{ Rosmarinus officinalis } & Cardiovascular & Acalma o coração & \multirow{5}{*}{ Folhas } & \multirow{2}{*}{ Infuso, macerado } \\
\hline & Digestivo & Digestivo & & \\
\hline & Nervoso & Calmante & & \\
\hline & Respiratório & Bronquite & & Fumaça \\
\hline & Urinário & Diurético & & Infuso, macerado \\
\hline \multirow{4}{*}{ Solanum paniculatum } & Digestivo & Problemas no fígado & \multirow{4}{*}{ Frutos } & \multirow{4}{*}{$\begin{array}{l}\text { Decocto } \\
\text { Macerado na pinga ou } \\
\text { vinho }\end{array}$} \\
\hline & Endócrino & Antidiabete & & \\
\hline & Imune & Infecções em geral & & \\
\hline & Musculoesquelético & Reumatismo & & \\
\hline
\end{tabular}

Rev. Bras. PI. Med., Campinas, v.18, n.2, p.451-461, 2016. 
e cavalinha não são nativas do Cerrado e, com exceção de cavalinha, todas pertencem a grupos filogenéticos derivados (Fabídeas, Lamídeas e Asterídeas), o que mostra um direcionamento da escolha de plantas medicinais nestes clados.

A maioria das espécies referenciadas neste trabalho é nativa do Cerrado (64\%), sendo que $70 \%$ daquelas com VUR maior que 10 , e $60 \%$ das mais versáteis em sistemas corporais são nativas. Esse fato evidencia a amplitude de conhecimento dos raizeiros sobre o uso medicinal da flora nativa local.

A maioria das referências etnobotânicas reporta o uso de folhas e raiz $(32,6 \%$ e $21,2 \%)$, sendo que chás - infusão ou decocção - foi a forma de preparo mais expressiva $(60,4 \%)$. Parece haver um direcionamento do uso de folhas sob a forma de chás nas práticas da medicina tradicional com o uso de plantas, como observado em outros trabalhos (Monteles \& Pinheiro, 2007; Souza, 2007).

Concluindo, a maioria das etnoespécies referenciadas pelos raizeiros de Jataí são plantas nativas do Cerrado pertencentes aos grupos mais derivados das angiospermas. Certamente, este representa o grupo maior de plantas, mas observase um direcionamento inconsciente na busca dos compostos químicos úteis nas práticas da medicina tradicional local. Esse fato é demonstrado pela ampla utilização de Equisetum hiemale, planta exótica pertencente a um grupo basal, porém com VUR maior que a maioria das angiospermas. Outro dado significativo do direcionamento inconsciente da busca de compostos químicos úteis nas práticas da medicina tradicional local é a forte utilização espécies das famílias Euphorbiaceae, Fabaceae, Asteraceae e Lamiaceae, amplamente reportadas em diversos trabalhos como portadoras de plantas medicinais. Os gêneros Croton, Chenopodium e Equisetum, no qual foram encontradas as etnoespécies com maior VUR, já fazem parte da listagem do Programa Nacional de Plantas Medicinais e Fitoterápicas, liberada pelo Ministério da Saúde do Brasil, para estudos de validação de farmacologia clínica; as espécies Psidium guajava, Solanum paniculatum, Copaifera spp. Plectranthus barbatus, Casearia sylvestris e Arrabidaea chica também são referidos no Programa. São evidências de que as plantas referidas na medicina tradicional de Jataí apresentam eficácia e são candidatas à investigações científicas nas áreas ecológica, agronômica, farmacológica e prospecção química, que validem o seu uso em modelos biomédicos. Os autores sugerem trabalhos aprofundados que avaliem a pressão de uso, sofrida pelas espécies nativas, considerando a destruição acentuada dos habitats naturais no município estudado.

\section{REFERÊNCIAS}

ALBUQUERQUE U.P et al. Métodos e técnicas para coleta de dados etnobotânicos. In: ALBUQUERQUE U.P et al. Métodos e técnicas na pesquisa etnobotânica. $2^{\circ}$ Ed., Recife: Comunigraf, 2008. p.41-72.

APG - ANGIOSPERM PHYLOGENETIC GROUP. An update of the Angiosperm Phylogeny Group classification for the orders and families of flowering plants: APG III.Botanical Journal of the Linnean Society, n.161, p.105-121, 2009.

BARROS, M.A. Flora medicinal do Distrito Federal. Brasil Florestal, v.50, p.35-45, 1982.

CHIARADIA, C. Dicionário de Palavras Brasileiras de Origem Indígena. 1'a. Ed. São Paulo: Ed. Limiar, 2008. 728 p.

CRUZ, G.L. Dicionário das plantas úteis do Brasil. $5^{\mathrm{a}} \mathrm{ed}$. Rio de Janeiro: Bertrand, 1995. 599 p.

FERNER, R. et al. Plantas utilizadas na medicina popular brasileira com potencial atividade antifúngica. Revista Brasileira de Ciências Farmacêuticas, v.42, n.3, p. 369-396. 2006.

FORZZA, R.C. et al. (Coord.) Lista de espécies da flora do Brasil. Jardim Botânico do Rio de Janeiro. Disponível em: <http://floradobrasil.jbrj.gov.br/>. Acesso em: 28 Ago. 2015.

GOMEZ-BELOZ, A. Plant knowledge of the Winikina Warao: the cases for questionnaire in ethnobotany. Economic Botany, n. 56, p.231-241, 2002.

GOTTLIEB, O.R.; BORIN, M.R.M.B. Quantitative Chemobiology: A Guide into the Understanding of Plant Bioactivity. Journal Brazilian Chemical Society, v.13, n.6, p.772-776, 2002.

GOTTLIEB, O.R.; BORIN, M.R.M.B. Químico-Biologia Quantitativa: Um Novo Paradigma? Química Nova, v.35, n.11, p.2105-2114, 2012.

GUARIM NETO, G.; MORAIS, R.G. Recursos medicinais de espécies do cerrado de mato grosso: um estudo bibliográfico. Acta Botânica Brasílica, v.17, n.4, p.561584, 2003.

KAPLAN, M.A.C. et al. Chemical diversity of plants from Brazilian Cerrados. Anais da Academia Brasileira de Ciências, n.66, p.50-55, 1994.

LEONTI, M. et al. Medicinal flora of the popoluca, Mexico: a botanical systematical perspective. Economic Botany, v. 57, n. 2, p. 218-230, 2003.

LORENZI, H.; MATOS, A.F.J. Plantas Medicinais no Brasil: nativas e exóticas. $2^{a}$. Edição. Nova Odessa: Instituto Plantarum de Estudos da Flora LTDA, 2002. $512 \mathrm{p}$.

MONTELES R.; PINHEIRO O.U.B. Plantas medicinais em um quilombo maranhense: uma perspectiva Etnobotânica. Revista Biológica e Ciência da Terra, v.7, n.2, 2007.

MORAIS, I.C. et al. Levantamento sobre plantas medicinais comercializadas em Goiânia: abordagem popular (raizeiros) e abordagem científica. Revista Eletrônica de Farmácia, v.2, n.1, p. 13-16, 2005.

OLIVEIRA, I.J. Dinâmica da ocupação das terras no município de Jataí (GO) e sua relação com o meio físico. Boletim Goiano de Geografia. v.27 n.2 p. 153179. 2007.

OLIVEIRA, D.M.S.; LUCENA, E.M.P. O uso de plantas

Rev. Bras. PI. Med., Campinas, v.18, n.2, p.451-461, 2016. 
medicinais por moradores de Quixadá-Ceará. Revista Brasileira de Plantas Medicinais, v.17, n.3, p. 407412, 2015.

OMS - ORGANIZAÇÃO MUNDIAL DA SAÚDE. Declaração De Alma-Ata. In: I Conferência Internacional Sobre Cuidados Primários De Saúde. Alma-Ata: OMS. 1978, 3p.

OMS - ORGANIZAÇÃO MUNDIAL DE SAÚDE. Classificação Internacional de Funcionalidade, Incapacidade e Saúde. Lisboa: OMS. 2004. 238p.

RIBEIRO, D.A. et al. Potencial terapêutico e uso de plantas medicinais em uma área de Caatinga no estado do Ceará, nordeste do Brasil. Revista Brasileira de Plantas Medicinais, v.16, n.4, p.912930, 2014.

SILVA, C.G. et al. Levantamento etnobotânico de plantas medicinais em área de Caatinga na comunidade do Sítio Nazaré, município de Milagres, Ceará, Brasil. Revista Brasileira de Plantas Medicinais, v.17, n.1, p.133-142, 2015.

SILVA, C.; PROENÇA, C.E.B. Uso e disponibilidade de recursos medicinais no município de Ouro Verde de Goiás, GO, Brasil. Acta Botânica Brasílica, v.22, n.2, p.481-492, 2008.

SILVA, S.C. et al. Caracterização climática do estado de Goiás. 1․ Edição. Goiânia: SIC/SGM/FUNMINERAL. 2006. 133 p.

SOUZA, L.F. Recursos vegetais usados na medicina tradicional do Cerrado (Comunidade de Baús, Acorizal, MT, Brasil). Revista Brasileira de Plantas Medicinais, v.9, n.4, p. $44-54,2007$.

VILLA-VERDE, G.M. et al. Levantamento etnobotânico das plantas medicinais do Cerrado utilizadas pela população de Mossâmedes GO. Revista Brasileira de Farmacognosia, v. 13, supl. 1, p. 64-66, 2003.

WHO - WORLD HEALTH ORGANIZATION. Traditional Medicine Strategy 2002-2005. Geneva: WHO. 2002. $61 \mathrm{p}$. 